\title{
Association of apolipoprotein E gene polymorphisms with blood lipids and their interaction with dietary factors
}

Israa M. Shatwan ${ }^{1,2}$, Kristian Hillert Winther ${ }^{3}$, Basma Ellahi ${ }^{4}$, Peter Elwood ${ }^{5}$, Yoav Ben-Shlomo $^{6}$, Ian Givens ${ }^{7}$, Margaret P. Rayman ${ }^{8}$, Julie A. Lovegrove ${ }^{1}$ and Karani S. Vimaleswaran ${ }^{1 *}$

\begin{abstract}
Background: Several candidate genes have been identified in relation to lipid metabolism, and among these, lipoprotein lipase ( $L P L)$ and apolipoprotein $E(A P O E)$ gene polymorphisms are major sources of genetically determined variation in lipid concentrations. This study investigated the association of two single nucleotide polymorphisms (SNPs) at LPL, seven tagging SNPs at the APOE gene, and a common APOE haplotype (two SNPs) with blood lipids, and examined the interaction of these SNPs with dietary factors.
\end{abstract}

Methods: The population studied for this investigation included 660 individuals from the Prevention of Cancer by Intervention with Selenium (PRECISE) study who supplied baseline data. The findings of the PRECISE study were further replicated using 1238 individuals from the Caerphilly Prospective cohort (CaPS). Dietary intake was assessed using a validated food-frequency questionnaire (FFQ) in PRECISE and a validated semi-quantitative FFQ in the CaPS. Interaction analyses were performed by including the interaction term in the linear regression model adjusted for age, body mass index, sex and country.

Results: There was no association between dietary factors and blood lipids after Bonferroni correction and adjustment for confounding factors in either cohort. In the PRECISE study, after correction for multiple testing, there was a statistically significant association of the APOE haplotype (rs7412 and rs429358; E2, E3, and E4) and APOE tagSNP rs445925 with total cholesterol $\left(P=4 \times 10^{-4}\right.$ and $P=0.003$, respectively). Carriers of the E2 allele had lower total cholesterol concentration $(5.54 \pm 0.97 \mathrm{mmol} / \mathrm{L})$ than those with the $\mathrm{E} 3(5.98 \pm 1.05 \mathrm{mmol} / \mathrm{L})(P=0.001)$ and $\mathrm{E} 4$ $(6.09 \pm 1.06 \mathrm{mmol} / \mathrm{L})\left(P=2 \times 10^{-4}\right)$ alleles. The association of APOE haplotype (E2, E3, and E4) and APOE SNP rs445925 with total cholesterol $\left(P=2 \times 10^{-6}\right.$ and $P=3 \times 10^{-4}$, respectively) was further replicated in the CaPS. Additionally, significant association was found between APOE haplotype and APOE SNP rs445925 with low density lipoprotein cholesterol in CaPS $\left(P=4 \times 10^{-4}\right.$ and $P=0.001$, respectively). After Bonferroni correction, none of the cohorts showed a statistically significant SNP-diet interaction on lipid outcomes.

Conclusion: In summary, our findings from the two cohorts confirm that genetic variations at the APOE locus influence plasma total cholesterol concentrations, however, the gene-diet interactions on lipids require further investigation in larger cohorts.

Keywords: APOE gene, Total cholesterol, LDL-C, PRECISE, Caerphilly prospective studies

\footnotetext{
* Correspondence: v.karani@reading.ac.uk

${ }^{1}$ Hugh Sinclair Unit of Human Nutrition and Institute for Cardiovascular and

Metabolic Research (ICMR), Department of Food and Nutritional Sciences,

University of Reading, Whiteknights, PO Box 226, Reading RG6 6AP, UK

Full list of author information is available at the end of the article
}

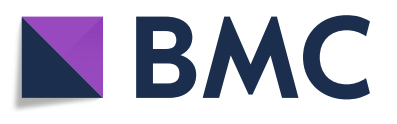

(c) The Author(s). 2018 Open Access This article is distributed under the terms of the Creative Commons Attribution 4.0 International License (http://creativecommons.org/licenses/by/4.0/), which permits unrestricted use, distribution, and

reproduction in any medium, provided you give appropriate credit to the original author(s) and the source, provide a link to the Creative Commons license, and indicate if changes were made. The Creative Commons Public Domain Dedication waiver (http://creativecommons.org/publicdomain/zero/1.0/) applies to the data made available in this article, unless otherwise stated. 


\section{Background}

Cardiovascular diseases (CVD) are common multifactorial conditions characterized by dyslipidaemia, type 2 diabetes and hypertension [1, 2]. Elevated triacylglycerol (TAG) and reduced high density lipoprotein cholesterol (HDL-C) concentrations are associated with an increased risk of developing CVD [3-5]. Furthermore, several studies have reported that certain genetic variants influence susceptibility to altered circulating lipid concentrations, leading to an increased risk of CVD events [6-8]. Genetic variations have been shown to be associated with lipid outcomes, while dietary factors appear to modulate the effect of such genes on lipid concentrations $[9,10]$. Previous studies have shown that single nucleotide polymorphisms (SNPs) of the apolipoprotein $\mathrm{E}$ $(A P O E)[6,11]$ and lipoprotein lipase $(L P L)$ [12-14] genes contribute to significant variation in lipid concentrations.

The APOE protein plays a key role in the transport and metabolism of cholesterol and TAG containing particles by serving as a receptor-binding ligand that mediates the clearance of dietary derived chylomicrons, and hepatically derived very low density lipoprotein (VLDL) and their remnants from the circulation [6]. The three most recognized alleles of the $A P O E$ gene are E2, E3 and E4, with carriage of E4 associated with CVD risk factors and increased low density lipoprotein cholesterol (LDLC) concentrations $[11,15,16]$, and hence increased CVD risk [17, 18].

Genetic variations in the $L P L$ gene have been reported to be involved with lipid metabolism and partly explain the phenotypic variation in blood lipid levels [19]. LPL is a lipolytic enzyme that catalyses hydrolysis of TAG in all of the major classes of TAG-rich lipoproteins [20]. High enzyme activity is associated with favourable lipid levels, including relatively low TAG concentrations [21]. The two most widely studied LPL SNPs, rs328 (S447X) and rs320 (HindIII) [22, 23]. The ' $G$ ' minor alleles of both the SNPs, rs328 and rs320, are associated with decreased TAG concentrations and increased HDL-C concentrations, whereas the opposite association was found for the ' $C$ ' allele and ' $T$ ' allele respectively [24-26].

Data from several studies supports the role of genetic factors in lipid metabolism [27]; however, only a few studies have examined the effects of lifestyle factors such as diet on the association of polymorphisms with lipidrelated outcomes [10, 28, 29]. Therefore, the present study aimed to investigate the effect of seven $A P O E$ tagSNPs (rs405509, rs769450, rs439401, rs445925, rs405697, rs1160985, and rs1064725), one APOE haplotype (rs7412 and rs429358), and two commonly studied LPL SNPs (rs328 and rs320) on blood lipid profile in 660 participants (baseline data) from the Prevention of Cancer by Intervention with Selenium (PRECISE) study.
As diet type and intake is also known to modify lipid levels [30-32], the potential impact of the interaction between these SNPs and dietary factors on lipid levels was also investigated. To confirm the findings, the Caerphilly Prospective Study (CaPS; $n=1238$ ) was used as a replication cohort.

\section{Methods \\ PRECISE cohort \\ Participants and methods}

Baseline data of 660 individuals from the PRECISE study, conducted in two populations [UK $(n=468)$ and Denmark $(n=192)]$ were used for the analysis [33, 34]. Briefly, study participants were selected from four general practices (study centres) in various areas of the UK that were affiliated with the Medical Research Council General Practice Research Framework (MRC GPRF). Between June 2000 and July 2001, research nurses recruited similar numbers of men and women from each of three age groups: $60-64,65-69$ and $70-74$ years. The Danish participants were men and women recruited from the same three age groups from the County of Funen in Denmark.

The UK study obtained approval from the appropriate UK Local Research Ethics Committees [South Tees (ref: 99/69), Worcestershire Health Authority (ref: LREC 74/ 99), Norwich District (ref: LREC 99/ 141), Great Yarmouth and Waveney (under reciprocal arrangements with Norwich District LREC)], and the participants provided written informed consent. The regional Danish Data Protection Agency and Scientific Ethical Committees of Vejle and Funen counties approved the Danish study (Journal number. 19980186).

\section{Dietary information}

Information about each participant's usual dietary intake was obtained using validated EPIC food frequency questionnaires (FFQ) [35]. Total energy intake and macronutrient composition were analysed using the FETA software program [36].

\section{Anthropometric measurements and biochemical analysis}

Body mass index (BMI) was calculated as body weight in kilograms divided by height in square metres $\left(\mathrm{kg} / \mathrm{m}^{2}\right)$. Participants provided non-fasting blood samples for biochemical analysis and these samples were stored at $-80{ }^{\circ} \mathrm{C}$. Total cholesterol and HDL-C concentrations in lithiumheparin plasma were measured using an Architect c16000 analyser (Abbott) with dedicated reagents. Measurements were performed by enzymatic colorimetric analysis. Traceability for total cholesterol and HDL-C was ensured through participation in the National Reference System for Cholesterol (NRS/CHOL), as established by the Clinical and Laboratory Standards Institute, with isotope dilution- 
MS used as the reference method, and reference material taken from the National Institute of Standard and Technology. Evidence of equivalence in the analytical performance of the cholesterol-oxidase assays performed in the UK and Denmark from a comparison of total cholesterol on fortyfour serum samples which produced a limit of variation of $2 \%[33]$.

\section{SNP selection}

The $A P O E$ gene is located on chromosome 19q13.32. It comprises four exons, which are transcribed into the APOE mRNA which is 1180 nucleotides long. The seven tagSNPs for the APOE gene were chosen based on International HapMap Phase II collected from individuals of Northern and Western European ancestry (CEU) (HapMap Data release 27 Phase $2+3$, Feb 09, NCBI B36 assembly, dbSNP b126). The Haploview software V3.3 (http://www.broadinstitute.org/haploview/haploviewdownloads) was used to assess the linkage disequilibrium between SNPs. Tagger software was used to select tagSNPs with the 'pairwise tagging only' option. Two criteria were used to filter the SNPs included in the analysis, minor allele frequency $\geq 5 \%$ and Hardy-Weinberg equilibrium $P$-value $>0.01$. In total, seven tagSNPs [rs405509 $(\mathrm{G}>\mathrm{T}), \operatorname{rs} 1160985(\mathrm{C}>\mathrm{T}), \operatorname{rs} 769450(\mathrm{G}>\mathrm{A})$, rs439401 $(\mathrm{C}>\mathrm{T}), \operatorname{rs} 445925(\mathrm{G}>\mathrm{A}), \operatorname{rs} 405697(\mathrm{G}>\mathrm{A})$, and $\operatorname{rs} 1064725(\mathrm{~T}>\mathrm{G})$ ] representing the entire common genetic variations across the $A P O E$ gene were selected for the study. The APOE haplotype/SNPs [6, 11, 37-44] and $L P L[12,13]$ SNPs were chosen based on their previous association with various lipid outcomes.

\section{DNA isolation and genotyping}

The genotyping for the selected SNPs using a KASP assay with a competitive allele-specific PCR assay ${ }^{\circ}$ was performed on DNA samples by LGC Genomics (Hoddesdon, Herts, UK). The eleven SNPs were in Hardy Weinberg Equilibrium (HWE) $(P>0.05$ for all comparisons) (Additional file 1: Table S1).

\section{Caerphilly prospective study (CaPS) Participants and methods}

The CaPS was used to replicate the findings from the PRECISE study. The phase 1 (July 1979 to September 1983) recruitment for the CaPS included 2512 men aged 45-59 years who were living in the town of Caerphilly and five of its adjacent villages in the UK; these participants were followed up at regular intervals $[45,46]$. The follow-up data collection included periods from 1984 to1988 (phase 2), from 1989 to 1993 (phase 3), from 1993 to 1997 (phase 4), and from 2002 to 2005 (phase $5)$. For the current study, the data analysed were taken from phase 3 ( $n=1238)$, which had the maximum number of samples and variables appropriate to this analysis (total cholesterol and dietary information), and from phase $5(n=529)$ (HDL-C and LDL-C). Ethical approval was obtained from the South Wales Research Ethics Committee D, and each subject provided written informed consent.

\section{Dietary information}

Participants completed validated semi-quantitative FFQ in phase 3 [47, 48]. The FFQ included 50 typical food items in the British diet in order to estimate the mean daily energy intake and macronutrients and micronutrients consumption.

\section{Anthropometric measurements and biochemical analysis}

Height and weight was recorded in order to calculate the BMI. Height was measured on a stadiometer and weight was measured on a beam balance. Plasm prepared from blood samples taken after an overnight fast were transported at $4{ }^{\circ} \mathrm{C}$ to the laboratories on the day of venepuncture. Total cholesterol and HDL-C, LDL-C concentrations were measured using enzymatic procedures [49]. and the LDL-C levels were calculated using the Friedewald Formula [50].

\section{DNA isolation and genotyping}

DNA was extracted from blood samples collected during the period 1992-1994. SNP information was obtained from the Illumina Cardio Metabochip, which includes data on 200,000 SNPs from regions previously identified for associations with risk factors for cardiometabolic disease [51]. Imputation was conducted against the 1000genomes reference panel, providing information on approximately two million typed or imputed SNPs. Duplicate samples were genotyped to compute the error rate. Quality control on genotyped samples has been previously reported [52] and the SNPs had a call rate of > $98 \%$. The SNPs were in HWE $(P>0.05)$ (Additional file 1: Table S1).

\section{Statistical analysis}

Statistical analysis was performed using the SPSS software package, version 22.0. The data were presented as mean \pm standard deviation (SD) in Tables 1 and 3 and beta regression coefficients and standard error (SE) were presented in Tables 2, 4, and 5. Independent t-test was used to compare means between men and women at baseline in the PRECISE cohort (Table 1). Univariate linear regression analysis was applied to test for association of the SNPs with total cholesterol and HDL-C, controlling for age, sex, BMI and country. SNP-diet interactions on total cholesterol and HDL-C were investigated using a univariate general linear model. In this model, total cholesterol and HDL-C were the dependent variables, SNPs were fixed factors, and dietary factors (fat energy 
Table 1 Baseline characteristics of the PRECISE and Caerphilly Prospective study participants

\begin{tabular}{|c|c|c|c|c|}
\hline \multirow[b]{2}{*}{ Characteristics } & \multicolumn{3}{|l|}{ PRECISE study } & \multirow{2}{*}{$\begin{array}{l}\text { Caerphilly Prospective study (CaPS) } \\
\text { Men } \\
(N=1238)\end{array}$} \\
\hline & $\begin{array}{l}\text { Men } \\
(N=248 \text { UK, } 95 \text { Danish) }\end{array}$ & $\begin{array}{l}\text { Women } \\
\text { (N=220 UK, } 97 \text { Danish) }\end{array}$ & $P$ value & \\
\hline Age (years) & $67 \pm 4$ & $67 \pm 4$ & 0.12 & $62 \pm 4$ \\
\hline Body mass index $\left(\mathrm{kg} / \mathrm{m}^{2}\right)$ & $27.2 \pm 4.9$ & $27.3 \pm 4.9$ & 0.82 & $26.8 \pm 3.7$ \\
\hline Total Cholesterol (mmol/L) & $5.6 \pm 0.9$ & $6.2 \pm 1.1$ & $2.31 \times 10^{-10}$ & $6.1 \pm 1.1$ \\
\hline High density lipoprotein cholesterol $(\mathrm{mmol} / \mathrm{L})^{\mathrm{a}}$ & $1.5 \pm 0.3$ & $1.7 \pm 0.4$ & $2.71 \times 10^{-16}$ & $1.3 \pm 0.3$ \\
\hline Protein intake (total energy \%) & $17.6 \pm 3.7$ & $18.8 \pm 3.7$ & $5 \times 10^{-5}$ & $14.9 \pm 2.7$ \\
\hline Carbohydrate intake (total energy \%) & $42.8 \pm 13.3$ & $48.2 \pm 8.7$ & $1.42 \times 10^{-9}$ & $48.4 \pm 7.5$ \\
\hline Fat intake (total energy \%) & $35.3 \pm 7.1$ & $33.9 \pm 6.9$ & 0.01 & $36.5 \pm 6.9$ \\
\hline Total energy intake (kcal) & $2256 \pm 658$ & $1992 \pm 613$ & $2.63 \times 10^{-7}$ & $1964 \pm 625$ \\
\hline Total energy intake (MJ) & $9.4 \pm 2.7$ & $8.3 \pm 2.6$ & $2.63 \times 10^{-7}$ & $8.2 \pm 2.6$ \\
\hline
\end{tabular}

Data shown are represented as means \pm SD, wherever appropriate. $P$ values are for the differences in the means between men and women. $P$ values were calculated by using independent t-test

${ }^{\mathrm{a}}$ For CaPS, HDL-C levels were obtained from phase 5 while all other variables were obtained from phase 3

$\%$, protein energy \%, carbohydrate energy \%), sex, age BMI, and country were covariates. The dominant model was applied for all SNPs with minor allele frequency $\leq 0$. 3 and the additive model applied for SNPs with minor allele frequency $\geq 0.4$. For analytical purposes, the six APOE genotype groups (E2/E2, E2/E3, E3/E3, E3/E4, E4/ $\mathrm{E} 4$, and E2/E4) were classified into three groups. The E3/E3 genotype was classified as a group as it occurs at high frequency in the population (wild type). The E2/E2 and E2/E3 genotypes were combined and presented as

Table 2 Association between dietary factors and lipids in PRECISE and Caerphilly Prospective studies

\begin{tabular}{|c|c|c|}
\hline \multicolumn{3}{|l|}{ PRECISE study } \\
\hline \multicolumn{3}{|c|}{ Association between dietary factors and total cholesterol } \\
\hline $\begin{array}{l}\text { Fat total energy } \% \\
\text { intake } \\
\text { Beta }( \pm \text { S.E) } \\
P_{\text {association }}\end{array}$ & $\begin{array}{l}\text { Protein total energy } \% \\
\text { intake } \\
\text { Beta }( \pm \text { S.E), Passociation }\end{array}$ & $\begin{array}{l}\text { Carbohydrate total energy } \\
\% \text { intake } \\
\text { Beta }\left( \pm \text { S.E), } P_{\text {association }}\right.\end{array}$ \\
\hline $\begin{array}{l}0.01(0.01) \\
0.47\end{array}$ & $\begin{array}{l}-0.01(0.01) \\
0.13\end{array}$ & $\begin{array}{l}-0.004(0.01) \\
0.40\end{array}$ \\
\hline \multicolumn{3}{|c|}{$\begin{array}{l}\text { Association between three dietary factors and HDL-C high density } \\
\text { lipoprotein }\end{array}$} \\
\hline $\begin{array}{l}\text { Fat total energy \% } \\
\text { intake }\end{array}$ & $\begin{array}{l}\text { Protein total energy \% } \\
\text { intake }\end{array}$ & $\begin{array}{l}\text { Carbohydrate total energy } \\
\% \text { intake }\end{array}$ \\
\hline $\begin{array}{l}-0.002(0.002) \\
0.29\end{array}$ & $\begin{array}{l}-0.002(0.004) \\
0.59\end{array}$ & $\begin{array}{l}-0.004(0.002) \\
0.02\end{array}$ \\
\hline \multicolumn{3}{|c|}{ Caerphilly Prospective study } \\
\hline \multicolumn{3}{|c|}{ Association between three dietary factors and total cholesterol } \\
\hline $\begin{array}{l}\text { Fat total energy } \% \\
\text { intake } \\
\text { Beta }( \pm \text { S.E), } \\
P_{\text {association }}\end{array}$ & $\begin{array}{l}\text { Protein total energy } \% \\
\text { intake } \\
\text { Beta }( \pm \text { S.E), Passociation }\end{array}$ & $\begin{array}{l}\text { Carbohydrate total energy } \\
\% \text { intake } \\
\text { Beta }\left( \pm \text { S.E), } P_{\text {association }}\right.\end{array}$ \\
\hline $\begin{array}{l}0.01(0.004) \\
0.06\end{array}$ & $\begin{array}{l}-0.01(0.01) \\
0.26\end{array}$ & $\begin{array}{l}-0.01(0.004) \\
0.17\end{array}$ \\
\hline
\end{tabular}

HDL-C, high density lipoprotein cholesterol

$P$ values were obtained using linear regression adjusted for age, sex, body mass index and country
E2 carriers. The E3/E4 and E4/E4 genotypes were also combined, and presented as E4 carriers [29]. Previous studies have shown that the impact of the E2 allele on serum lipids is greater than that of the E4 allele [17], therefore, the E2/E4 genotype was excluded from the analysis. The Bonferroni correction was applied separately for association and interaction analyses. For association between phenotypic and dietary factors, the Bonferroni-corrected $P$ value was 0.008 (2 lipid outcomes* 3 dietary factors) for the PRECISE study and $\mathrm{P}$ value was 0.01 for CaPS (total cholesterol was the only variable available). For association between SNPs and lipids (PRECISE study), the Bonferroni corrected $\mathrm{P}$ value was 0.003 (10 SNPs*2 lipid outcomes $=20$ tests $)$. For interactions (PRECISE study), the Bonferroni corrected P value was 0.001 (10 SNPs*2 lipid outcomes*3 dietary factors $=60$ tests). In the replication analysis (CaPS cohort), the Bonferroni corrected $\mathrm{P}$ value for association was 0 . 002 (10 SNPs*3 lipid outcomes = 30 tests), while for interactions it was 0.001 (10 SNPs*1 lipid outcome* 3 dietary factors $=30$ tests).

\section{Results \\ Participant characteristics}

The general characteristics of the participants by sex are presented in Table 1. In the PRECISE study, women were found to have significantly higher total cholesterol and HDL-C concentrations than men $\left(P=2.31 \times 10^{-10}\right.$ and $P=2.71 \times 10^{-16}$, respectively). The consumption of carbohydrates $\left(P=1.42 \times 10^{-9}\right)$ and protein (energy \%) $\left(P=5 \times 10^{-5}\right)$ were higher in women than in men, whereas the consumption of fat (energy \%) and total energy intake were lower in women than in men $(P=0$. 01). Characteristics of the individuals from CaPS are given in Table 1. Elevated total cholesterol levels were 
observed among men at phase 3. Dietary-pattern data showed higher consumption of energy from total fat.

\section{Association between dietary factors and blood lipids}

In both the PRECISE and CaPS, there was no association between the dietary factors and total cholesterol or highdensity lipoprotein after Bonferroni correction and adjustment for confounding factors (Table 2).

\section{Genotypes and serum lipid levels in the PRECISE study}

As shown in Table 3, of the seven tagSNPs at APOE, tagSNP rs445925 was significantly associated with total cholesterol $(P=0.003)$ after correction for multiple testing. The 'A' allele carriers $(5.65 \pm 0.98 \mathrm{mmol} / \mathrm{L})$ had $5 \%$ lower levels of total cholesterol than GG homozygotes $(5.99 \pm 1$. $06 \mathrm{mmol} / \mathrm{L}$ ).

The levels of HDL-C were significantly different among the LPL SNP genotypes, $\operatorname{rs} 328(P=0.04)$ and rs320 $(P=0.02)$, where the carriers of the ' $\mathrm{G}$ ' minor allele of both SNPs had higher levels of HDL-C $(1.68 \pm 0$. $41 \mathrm{mmol} / \mathrm{L}$ for $\mathrm{rs} 328$ and $1.66 \pm 0.40 \mathrm{mmol} / \mathrm{L}$ for $\mathrm{rs} 320$ ) than CC homozygotes (rs328) and TT homozygotes (rs320) $(1.61 \pm 0.38$ and $1.60 \pm 0.39 \mathrm{mmol} / \mathrm{L})$ respectively. However, these associations were not statistically significant after Bonferroni correction.

\section{APOE haplotype and serum lipid levels in the PRECISE study}

The effects of $A P O E$ haplotypes (E2, E3, and E4) on serum lipids are shown in Table 3. These haplotypes (E2, $\mathrm{E} 3$, and E4) were significantly associated with total cholesterol $\left(P=4 \times 10^{-4}\right)$ after correction for multiple testing. The carriers of the E2 allele $(5.54 \pm 0.97 \mathrm{mmol} /$ L) had lower total cholesterol concentrations than the carriers of the E3 $(P=0.001)(5.98 \pm 1.05 \mathrm{mmol} / \mathrm{L})$ and E4 alleles $(6.09 \pm 1.06 \mathrm{mmol} / \mathrm{L})\left(P=2 \times 10^{-4}\right)$ (Fig. 1).

\section{Interactions between genotypes and dietary factors on serum lipid in the PRECISE study}

None of the dietary factors significantly interacted with the APOE SNPs, haplotypes and LPL SNPs with plasma lipids after correction for multiple testing $(P>0.001)$ (Table 4).

\section{Replication analysis: Effect of SNPs at APOE and LPL on serum lipids in the CaPS}

The associations of $A P O E$ and $L P L$ SNPs with blood lipids in the CaPS are presented in Table 3. The association of $A P O E$ haplotype (E2, E3, and E4) and $A P O E$ SNP rs445925 with total cholesterol $\left(\mathrm{P}=2 \times 10^{-6}\right.$ and $P$ $=3 \times 10^{-4}$, respectively) was replicated (Fig. 1). The 'A' allele carriers of APOE SNP rs445925 had lower total cholesterol (5.96 $\pm 1.24 \mathrm{mmol} / \mathrm{l})$ than 'GG' genotypes (6.24 $\pm 1.08 \mathrm{mmol} / \mathrm{L})$. In the $A P O E$ haplotype analysis, the carriers of the E2 allele had $5 \%$ and $14 \%$ lower total cholesterol than carriers of the E3 $\left(P=4 \times 10^{-4}\right)$ and E4 alleles $\left(\mathrm{P}=3 \times 10^{-6}\right)$, respectively. Additionally, significant association was seen between $A P O E$ haplotypes (E2, E3, and E4) and APOE SNP rs445925and LDL-C $\left(\mathrm{P}=4 \mathrm{X}^{-4}{ }^{-4}\right.$, 0.001 , respectively).

There was an interaction between fat (\% energy) and $A P O E$ haplotype (E2, E3, and E4) on total cholesterol (P $=0.038)$ in CaPS. However, after correction for multiple testing, all the SNP-diet interactions were consistent with chance variation (Table 5).

\section{Discussion}

Our findings demonstrated significant associations between the APOE haplotype (E2, E3, and E4) and APOE SNP rs445925 with total plasma cholesterol and LDL-C (only CaPS) concentration, which were further replicated in an independent UK Caucasian cohort. The levels of total cholesterol were significantly lower in carriers of the $A P O E \mathrm{E} 2$ allele and the 'A' allele of the SNP rs445925 than carriers of E3, E4 and 'GG' genotype of the APOE SNP rs445925, respectively. Given that our findings confirm that genetic polymorphisms of $A P O E$ influence the inter-individual variation in total plasma cholesterol, a marker of dyslipidemia, changes in dietary consumption to reduce disease susceptibility could be implemented for individuals at genetic risk.

The effects of $A P O E$ polymorphisms on lipid concentrations have previously been investigated in different ethnic groups [11, 53,54] and studies have shown that the $A P O E$ gene variants contributed to $7 \%$ variability in total cholesterol [55]. The results of the current study were in line with previously reported findings that $A P O E$ haplotypes (E2, E3, and E4) are associated with serum total cholesterol and LDL-C, with E4 carriers associated with increased concentrations compared with E3/E3 wildtype and particularly E2 carriers $[16,53,56]$. One of the primary roles of APOE is binding the low density lipoprotein receptor (LDLR) and the LDLR-related protein, to facilitate cellular uptake of lipoprotein particles [57]. The three alleles, E2, E3, and E4, differ in their amino-acid sequences, resulting in functional differences in receptors-binding affinity. Amino-acid sequences of the E2 allele have lower binding affinity than those of the E3 and E4 alleles, causing decreased hepatic VLDL and chylomicron remnants clearance, thus reducing the uptake of postprandial lipoprotein particles [57]. Furthermore, it could be postulated that increase in apoE TAG-rich lipoproteins in E4 carriers could possibly increase the affinity to bind LDL-receptors resulting in decreased uptake of LDL and increased circulating plasma cholesterol [58]. E2 carriers also have an impaired 
Table 3 Association of APOE and LPL SNPS with HDL-C and total cholesterol levels in the PRECISE and Caerphilly studies

\begin{tabular}{|c|c|c|c|c|}
\hline SNP & MAF & $\mathrm{HDL}-\mathrm{C}(\mathrm{mmol} / \mathrm{L})$ & Total Cholesterol (mmol/L) & $\mathrm{LDL}-\mathrm{C}^{\mathrm{a}}(\mathrm{mmol} / \mathrm{L})$ \\
\hline \multicolumn{5}{|l|}{ PRECISE } \\
\hline \multicolumn{5}{|l|}{$L P L$} \\
\hline rs320 & 0.26 & & & \\
\hline$\pi$ & & $1.6 \pm 0.3$ & $5.9 \pm 1.1$ & \\
\hline $\mathrm{T} / \mathrm{G}$ & & $1.7 \pm 0.4$ & $5.8 \pm 1.0$ & \\
\hline$P$ value & & 0.02 & 0.19 & \\
\hline rs328 & 0.10 & & & \\
\hline $\mathrm{CC}$ & & $1.6 \pm 0.3$ & $5.9 \pm 1.1$ & \\
\hline$C / G$ & & $1.7 \pm 0.4$ & $5.7 \pm 0.9$ & \\
\hline$P$ value & & 0.04 & 0.06 & \\
\hline \multicolumn{5}{|l|}{$A P O E$} \\
\hline rs405509 & 0.47 & & & \\
\hline GG & & $1.7 \pm 0.4$ & $5.8 \pm 1.1$ & \\
\hline GT & & $1.5 \pm 0.3$ & $5.8 \pm 1.1$ & \\
\hline$\pi$ & & $1.6 \pm 0.3$ & $6.1 \pm 1.0$ & \\
\hline$P$ value & & 0.07 & 0.23 & \\
\hline rs769450 & 0.39 & & & \\
\hline GG & & $1.6 \pm 0.3$ & $5.9 \pm 1.1$ & \\
\hline A allele & & $1.6 \pm 0.4$ & $5.9 \pm 1.1$ & \\
\hline$P$ value & & 0.72 & 0.97 & \\
\hline rs439401 & 0.33 & & & \\
\hline $\mathrm{CC}$ & & $1.6 \pm 0.4$ & $5.9 \pm 1.1$ & \\
\hline T allele & & $1.6 \pm 0.3$ & $5.9 \pm 1.1$ & \\
\hline$P$ value & & 0.43 & 0.51 & \\
\hline rs445925 & 0.11 & & & \\
\hline GG & & $1.6 \pm 0.3$ & $5.9 \pm 1.1$ & \\
\hline A allele & & $1.7 \pm 0.4$ & $5.6 \pm 0.9$ & \\
\hline$P$ value & & 0.25 & 0.003 & \\
\hline rs405697 & 0.25 & & & \\
\hline GG & & $1.6 \pm 0.4$ & $5.9 \pm 1.1$ & \\
\hline A allele & & $1.6 \pm 0.3$ & $5.9 \pm 1.0$ & \\
\hline$P$ value & & 0.71 & 0.96 & \\
\hline rs1160985 & 0.43 & & & \\
\hline $\mathrm{CC}$ & & $1.6 \pm 0.3$ & $5.9 \pm 1.1$ & \\
\hline CT & & $1.6 \pm 0.4$ & $5.8 \pm 1.0$ & \\
\hline$\pi$ & & $1.7 \pm 0.4$ & $5.9 \pm 1.1$ & \\
\hline$P$ value & & 0.12 & 0.44 & \\
\hline rs1064725 & 0.04 & & & \\
\hline$\pi$ & & $1.6 \pm 0.4$ & $5.9 \pm 1.0$ & \\
\hline $\mathrm{G}$ allele & & $1.7 \pm 0.3$ & $6.1 \pm 1.2$ & \\
\hline$P$ value & & 0.17 & 0.38 & \\
\hline \multicolumn{5}{|c|}{ (rs7412-rs429358) E2, E3, and E4 } \\
\hline E3 & & $1.6 \pm 0.3$ & $5.9 \pm 1.1$ & \\
\hline E4 & & $1.5 \pm 0.3$ & $6.1 \pm 1.1$ & \\
\hline
\end{tabular}


Table 3 Association of APOE and LPL SNPs with HDL-C and total cholesterol levels in the PRECISE and Caerphilly studies (Continued)

\begin{tabular}{|c|c|c|c|c|}
\hline SNP & MAF & $\mathrm{HDL}-\mathrm{C}(\mathrm{mmol} / \mathrm{L})$ & Total Cholesterol (mmol/L) & $\mathrm{LDL}-\mathrm{C}^{\mathrm{a}}(\mathrm{mmol} / \mathrm{L})$ \\
\hline E2 & & $1.7 \pm 0.4$ & $5.5 \pm 0.9$ & \\
\hline$P$ value & & 0.09 & $4 \times 10^{-4}$ & \\
\hline \multicolumn{5}{|l|}{ Caerphilly } \\
\hline \multicolumn{5}{|l|}{$L P L$} \\
\hline rs320 & 0.26 & & & \\
\hline$\pi$ & & $1.3 \pm 0.3$ & $6.1 \pm 1.1$ & $2.7 \pm 0.8$ \\
\hline$T / G$ & & $1.4 \pm 0.3$ & $6.2 \pm 1.2$ & $2.8 \pm 0.8$ \\
\hline$P$ value & & 0.05 & 0.55 & 0.05 \\
\hline rs328 & 0.10 & & & \\
\hline $\mathrm{CC}$ & & $1.3 \pm 0.3$ & $6.1 \pm 1.1$ & $2.7 \pm 0.8$ \\
\hline$C / G$ & & $1.3 \pm 0.3$ & $6.1 \pm 1.1$ & $2.9 \pm 0.9$ \\
\hline$P$ value & & 0.63 & 0.71 & 0.05 \\
\hline \multicolumn{5}{|l|}{$A P O E$} \\
\hline rs405509 & 0.46 & & & \\
\hline GG & & $1.4 \pm 0.3$ & $6.0 \pm 1.1$ & $2.7 \pm 0.9$ \\
\hline GT & & $1.3 \pm 0.3$ & $6.2 \pm 1.1$ & $2.8 \pm 0.8$ \\
\hline$\pi$ & & $1.3 \pm 0.3$ & $6.3 \pm 1.1$ & $2.9 \pm 0.9$ \\
\hline$P$ value & & 0.16 & 0.02 & 0.29 \\
\hline rs769450 & 0.41 & & & \\
\hline GG & & $1.3 \pm 0.2$ & $6.1 \pm 1.2$ & $2.8 \pm 0.9$ \\
\hline A allele & & $1.4 \pm 0.3$ & $6.2 \pm 1.1$ & $2.8 \pm 0.8$ \\
\hline$P$ value & & 0.10 & 0.41 & 0.82 \\
\hline rs439401 & 0.35 & & & \\
\hline CC & & $1.4 \pm 0.3$ & $6.2 \pm 1.1$ & $2.8 \pm 0.9$ \\
\hline T allele & & $1.3 \pm 0.3$ & $6.1 \pm 1.1$ & $2.7 \pm 0.8$ \\
\hline$P$ value & & 0.72 & 0.42 & 0.32 \\
\hline rs445925 & 0.11 & & & \\
\hline GG & & $1.3 \pm 0.3$ & $6.2 \pm 1.1$ & $2.8 \pm 0.8$ \\
\hline A allele & & $1.3 \pm 0.3$ & $5.9 \pm 1.2$ & $2.5 \pm 0.9$ \\
\hline$P$ value & & 0.99 & $3 \times 10^{-4}$ & 0.001 \\
\hline rs405697 & 0.26 & & & \\
\hline GG & & $1.4 \pm 0.4$ & $6.1 \pm 1.1$ & $2.8 \pm 0.9$ \\
\hline A allele & & $1.3 \pm 0.3$ & $6.1 \pm 1.1$ & $2.8 \pm 0.8$ \\
\hline$P$ value & & 0.30 & 0.88 & 0.9 \\
\hline rs1160985 & 0.45 & & & \\
\hline $\mathrm{CC}$ & & $1.34 \pm 0.29$ & $6.2 \pm 1.1$ & $2.8 \pm 0.9$ \\
\hline$C T$ & & $1.35 \pm 0.35$ & $6.2 \pm 1.2$ & $2.7 \pm 0.8$ \\
\hline$\pi$ & & $1.37 \pm 0.40$ & $6.1 \pm 1.0$ & $2.8 \pm 0.8$ \\
\hline$P$ value & & 0.61 & 0.30 & 0.73 \\
\hline rs1064725 & 0.01 & & & \\
\hline$\pi$ & & $1.3 \pm 0.3$ & $6.2 \pm 1.1$ & $2.8 \pm 0.8$ \\
\hline G allele & & $1.4 \pm 0.3$ & $6.1 \pm 1.1$ & $2.8 \pm 0.7$ \\
\hline$P$ value & & 0.18 & 0.60 & 0.68 \\
\hline
\end{tabular}


Table 3 Association of APOE and LPL SNPs with HDL-C and total cholesterol levels in the PRECISE and Caerphilly studies (Continued)

\begin{tabular}{|c|c|c|c|c|}
\hline SNP & MAF & $\mathrm{HDL}-\mathrm{C}(\mathrm{mmol} / \mathrm{L})$ & Total Cholesterol (mmol/L) & $\mathrm{LDL}-\mathrm{C}^{\mathrm{a}}(\mathrm{mmol} / \mathrm{L})$ \\
\hline E3 & & $1.4 \pm 0.4$ & $6.2 \pm 1.1$ & $2.8 \pm 0.8$ \\
\hline E4 & & $1.4 \pm 0.3$ & $6.4 \pm 1.1$ & $3.0 \pm 0.9$ \\
\hline E2 & & $1.3 \pm 0.3$ & $5.8 \pm 1.3$ & $2.4 \pm 0.8$ \\
\hline$P$ value & & 0.95 & $2 \times 10^{-6}$ & $4 \times 10^{-4}$ \\
\hline
\end{tabular}

Values are given as mean \pm SD. $P$ values for differences between genotypes were obtained using linear regression model adjusted for age, sex, body mass index, and country

Bonferroni corrected $P$ value $<0.003$ was considered statistically significant

MAF minor allele frequency, $H D L-C$ high density lipoprotein cholesterol, $L D L-C$ low density lipoprotein cholesterol

${ }^{a}$ LDL-C values available only in Caerphilly prospective study

conversion of the VLDL particles to LDL-C compared to E4 carriers [59], who have a higher rate of VLDL catabolism [60], which explains in part the lower total cholesterol and LDL-C in E2 allele carriers.

Furthermore, our study highlights an association between APOE SNP rs445925, which is one of the selected tagSNPs within the APOE gene, and total cholesterol. The SNP rs445925 has not been extensively studied, however, a genome-wide association study showed a significant association between SNP rs445925 and LDL-C levels in 3644 black and white individuals from the US and Europe [61]. In addition, previous genome-wide linkage and association studies have shown linkage disequilibrium (LD) between $A P O E$ SNPs rs7412 and rs445925 [62] and between 'A' allele carriers at SNP rs445925 and E2 haplotype [63], respectively, which could explain in part a similar function in cholesterol synthesis. It is also possible that $\mathrm{A}^{\prime}$ allele carriers of the SNP rs445925 might exhibit lower conversion of the VLDL particles to LDL-C which could have resulted in the decreased rate of LDL formation and hence lowered the total cholesterol concentrations [63].
Besides genetic associations, our study also identified an interaction of $A P O E$ haplotypes (E2, E3, and E4) with intake from fat (\%) on total cholesterol in the CaPS, where, among those who consumed a low-fat diet (\%), individuals carrying the E2 allele had significantly lower total cholesterol concentrations than to E4 allele carriers. However, this interaction was not statistically significant after correction for multiple testing. A previous study has examined the response of $A P O E$ genotype to fat intake in 45 individuals using a prospective design, where after consumption of a lower-fat-cholesterol diet (34\% fat, $265 \mathrm{mg} /$ day) according to modified National Cholesterol Education program there was a significant reduction in total cholesterol by $14 \%, 9 \%$, and $4 \%$ in $\mathrm{E} 4 /$ E4, E3/E4, and E3/E3 genotypes, respectively [64]. Another study showed that the response to a diet high in cholesterol increases total cholesterol in E3 and E4 compared to E2 allele carries in a study comprising 29 healthy men [65]. By contrast, a cross sectional study in European Caucasians $(n=996)$ reported that E2 allele carriers had lower total cholesterol levels, but there were no reported between interactions between saturated fatty

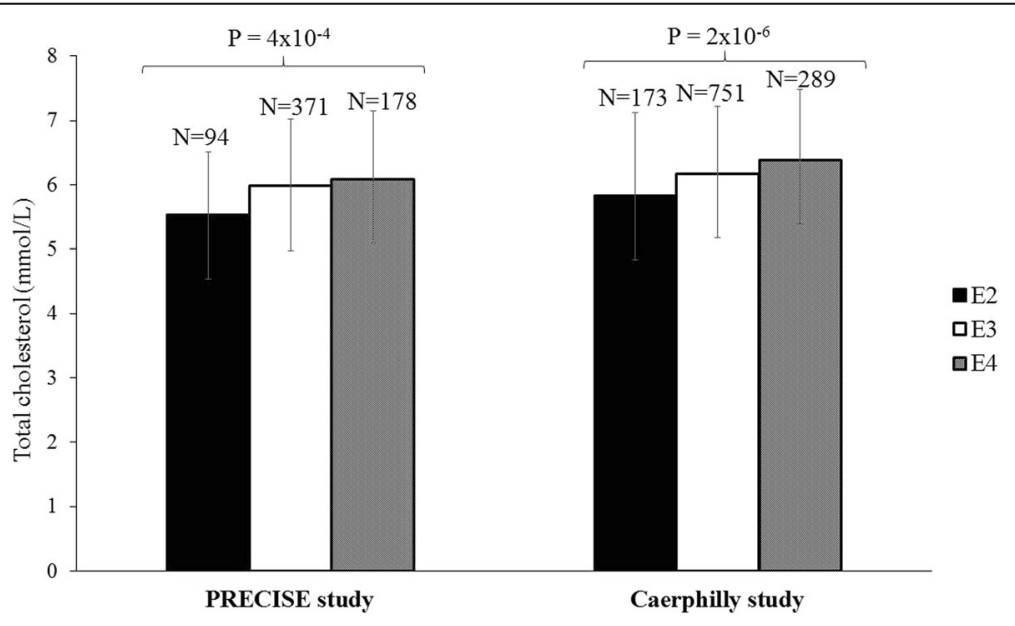

Fig. 1 Association of APOE haplotypes (E2, E3, and E4) with total cholesterol concentrations in the Prevention of Cancer by Intervention with Selenium (PRECISE) study and Caerphilly Prospective study (CaPS). E2 allele carriers have significantly lower levels of total cholesterol than E3 $\left(P=0.001\right.$ and $P=4 \times 10^{-4}$ in the PRECISE and CaPS, respectively) and E4 $\left(P=2 \times 10^{-4}\right.$ and $P=3 \times 10^{-6}$ in the PRECISE and CaPS, respectively) allele carriers 
Table 4 Interaction between APOE and LPL SNPs and dietary factors on HDL-C and total cholesterol in the PRECISE study

\begin{tabular}{lll}
\hline Interaction between rs320 at $L P L^{*}$ dietary factors on HDL-C & \\
\hline $\begin{array}{lll}\text { Interaction between SNP rs320* fat energy } \% & \text { Interaction between SNP rs320* protein energy } \\
\text { intake } & \% \text { intake } & \begin{array}{l}\text { Interaction between SNP rs320* carbohydrate } \\
\text { energy \% intake }\end{array} \\
0.003(0.004) & 0.002(0.01) & -0.0004(0.002) \\
0.46 & 0.76 & 0.87 \\
\text { Interaction between rs320 at } L P L \text { * dietary factors on Total Cholesterol } & \\
\text { Interaction between SNP rs320* fat energy \% } & \text { Interaction between SNP rs320* protein energy } & \text { Interaction between SNP rs } 320^{*} \text { carbohydrate } \\
\text { intake } & \% \text { intake } & \text { energy \% intake } \\
0.01(0.01) & -0.03(0.02) & -0.01(0.01) \\
0.27 & 0.13 & 0.06\end{array}$
\end{tabular}

Interaction between rs328 at $L P L$ *dietary factors on $\mathrm{HDL}-\mathrm{C}$

Interaction between SNP rs328* fat energy \% Interaction between SNP rs328* protein energy intake $\%$ intake

Interaction between SNP rs328* carbohydrate energy \% intake

$0.01(0.01)$

$-0.001(0.01)$

0.09

0.89

$0.001(0.003)$

0.63

Interaction between rs328 at $L P L{ }^{*}$ dietary factors on Total Cholesterol

Interaction between SNP rs $328^{*}$ fat energy \% Interaction between SNP rs328* protein energy intake $\%$ intake

Interaction between SNP rs328* carbohydrate energy \% intake

$-0.002(0.02)$

$0.003(0.03)$

0.88

0.90

$-0.01(0.01)$

0.55

Interaction between rs405509 at APOE* dietary factors on $\mathrm{HDL}-\mathrm{C}$

Interaction between SNP rs405509* fat Interaction between SNP rs405509* protein energy \% intake energy \% intake

Interaction between SNP rs405509* carbohydrate energy \% intake

$-0.01(0.003)$

0.09

0.11

$-0.001(0.01)$

0.75

Interaction between rs405509 at APOE * dietary factors on Total Cholesterol

Interaction between SNP rs405509* fat Interaction between SNP rs405509* protein energy \% intake energy \% intake

Interaction between SNP rs405509* carbohydrate energy \% intake

$\begin{array}{ll}0.02(0.02) & -0.04(0.03) \\ 0.39 & 0.26\end{array}$

$-0.01(0.01)$

0.59

Interaction between rs769450 at APOE * dietary factors on HDL-C

Interaction between SNP rs769450* fat Interaction between SNP rs769450* protein energy \% intake

\section{energy \% intake}

$0.001(0.01)$

0.88

0.88

y factors on Total Cholesterol

Interaction between rs769450 at APOE
Interaction between SNP rs769450* fat energy \% intake

Interaction between SNP rs769450* protein energy \% intake

$-0.001(0.01)$

$0.01(0.02)$

0.63

Interaction between rs439401 at APOE *dietary factors on HDL-C

Interaction between SNP rs439401* fat Interaction between SNP rs439401* protein energy \% intake energy \% intake
$0.01(0.004)$
$0.01(0.01)$
0.11
0.39

Interaction between rs439401 at APOE * dietary factors on Total Cholesterol

Interaction between SNP rs439401* fat Interaction between SNP rs439401* protein energy \% intake energy \% intake
$0.003(0.01)$
$-0.02(0.02)$
0.79
0.37

Interaction between rs445925 at APOE *dietary factors on HDL-C

Interaction between SNP rs445925* fat Interaction between SNP rs445925* protein energy \% intake
Interaction between SNP rs445925* protein
energy \% intake
Interaction between SNP rs769450* carbohydrate energy \% intake

$0.003(0.003)$

0.19

Interaction between SNP rs769450* carbohydrate energy \% intake

$0.01(0.01)$

0.51

Interaction between SNP rs439401* carbohydrate energy \% intake

$-0.001(0.003)$

0.64

Interaction between SNP rs439401* carbohydrate energy \% intake

$-0.001(0.01)$

0.89

Interaction between SNP rs445925* carbohydrate energy \% intake 
Table 4 Interaction between APOE and LPL SNPS and dietary factors on HDL-C and total cholesterol in the PRECISE study (Continued)

Interaction between rs320 at $L P L^{*}$ dietary factors on $\mathrm{HDL}-\mathrm{C}$

\begin{tabular}{lll}
\hline$-0.003(0.01)$ & $0.01(0.01)$ & $0.0003(0.003)$ \\
0.53 & 0.52 & 0.93
\end{tabular}

Interaction between rs445925 at APOE *dietary factors on Total Cholesterol

Interaction between SNP rs445925* fat Interaction between SNP rs445925* protein energy \% intake energy \% intake

$\begin{array}{ll}-0.03(0.01) & 0.01(0.03) \\ 0.05 & 0.66\end{array}$

Interaction between rs405697 at APOE *dietary factors on HDL-C

Interaction between SNP rs405697* fat Interaction between SNP rs405697* protein energy \% intake energy \% intake

$0.01(0.004)$

0.06

$$
-0.002(0.01)
$$$$
0.80
$$

Interaction between rs405697 at APOE * dietary factors on Total Cholesterol

$$
\text { Interaction between SNP rs405697* fat }
$$
energy \% intake

Interaction between SNP rs405697* protein energy \% intake

$0.01(0.01)$

$-0.03(0.02)$

0.22

0.19

Interaction between rs1160985 at APOE *dietary factors on HDL-C

Interaction between SNP rs1160985* fat energy \% intake

Interaction between SNP rs1160985* protein energy \% intake

$-0.01(0.01)$

0.08

$-0.002(0.01)$

0.97

Interaction between rs1160985 at APOE * dietary factors on Total Cholesterol

Interaction between SNP rs1 160985* fat Interaction between SNP rs1160985* protein energy \% intake energy \% intake
$-0.01(0.01)$
$0.05(0.03)$
0.58
0.28

Interaction between rs 1064725 at $A P O E$ *dietary factors on $\mathrm{HDL}-\mathrm{C}$

Interaction between SNP rs 1064725* fat Interaction between SNP rs 1064725* protein energy \% intake

\section{energy \% intake}

$-0.001(0.01)$

0.90

$0.004(0.02)$

0.77

Interaction between rs1064725 at APOE *dietary factors on Total Cholesterol

$\begin{array}{ll}\text { Interaction between SNP rs } 1064725^{*} \text { fat } & \begin{array}{l}\text { Interaction between SNP rs1064725* protein } \\ \text { energy \% intake }\end{array} \\ \text { energy \% intake } & 0.02(0.04) \\ 0.03(0.03) & 0.62\end{array}$

Interaction between $A P O E(E 2, E 3 \text {, and } E 4)^{*}$ dietary factors on $\mathrm{HDL}-\mathrm{C}$

Interaction between SNP APOE (E2, E3, and Interaction between SNP APOE (E2, E3, and E4)* E4)* fat energy \% intake protein energy $\%$ intake

$\begin{array}{ll}-0.01(0.01) & 0.001(0.01) \\ 0.39 & 0.99\end{array}$

0.39

0.99

Interaction between SNP rs445925* carbohydrate energy \% intake

$0.01(0.01)$

0.36

Interaction between SNP rs405697* carbohydrate energy \% intake

$-0.004(0.002)$

0.16

Interaction between SNP rs405697* carbohydrate energy \% intake

$-0.003(0.01)$

0.72

Interaction between SNP rs1160985* carbohydrate energy \% intake

$0.01(0.004)$

0.03

Interaction between SNP rs1160985* carbohydrate energy \% intake

$-0.001(0.01)$

0.19

Interaction between SNP rs1064725* carbohydrate energy \% intake

$-0.002(0.004)$

0.73

Interaction between SNP rs1064725* carbohydrate energy \% intake

$-0.01(0.01)$

0.48

Interaction between SNP APOE (E2, E3, and E4)* carbohydrate energy \% intake

$0.002(0.003)$

0.17

Interaction between $A P O E(E 2, E 3$, and E4)*dietary factors on Total Cholesterol

Interaction between SNP APOE (E2, E3, and Interaction between SNP APOE (E2, E3, and E4)* E4)* fat energy \% intake protein energy $\%$ intake

Interaction between SNP APOE (E2, E3, and E4)* carbohydrate energy \% intake

$0.01(0.01)$

0.51

0.18

$$
0.32
$$

Values represented $\beta$ regression coefficients $\left( \pm\right.$ S.E), and $P_{\text {interaction. }} P$ values were obtained by using a general linear model adjusted for age, sex, body mass index, country and total energy intake, wherever appropriate Bonferroni corrected $P$ value $<0.001$ was considered statistically significant HDL-C High density lipoprotein cholesterol 
Table 5 Interaction between APOE and LPL SNPs and dietary factors on total cholesterol in the CaPS Interaction between rs320 at $L P L$ *dietary factors on Total Cholesterol

\begin{tabular}{lll}
\hline $\begin{array}{l}\text { Interaction between SNP rs320* fat energy \% } \\
\text { intake }\end{array}$ & $\begin{array}{l}\text { Interaction between SNP rs320* protein energy } \\
\% \text { intake }\end{array}$ & $\begin{array}{l}\text { Interaction between SNP rs320* carbohydrate } \\
\text { energy \% intake }\end{array}$ \\
$0.01(0.01)$ & $-0.01(0.03)$ & $-0.004(0.01)$ \\
0.48 & 0.57 & 0.64
\end{tabular}

Interaction between rs328 at $L P L$ *dietary factors on Total Cholesterol

Interaction between SNP rs328* fat energy \% Interaction between SNP rs328* protein energy intake

$\%$ intake

Interaction between SNP rs328* carbohydrate energy \% intake

$-0.01(0.01)$

$-0.04(0.03)$

0.58

0.17

$0.01(0.01)$

0.29

Interaction between rs405509 at APOE *dietary factors on Total Cholesterol

Interaction between SNP rs405509* fat Interaction between SNP rs405509* protein energy \% intake energy \% intake

$0.03(0.01)$

$-0.04(0.04)$

0.11

0.52

Interaction between rs769450 at APOE *dietary factors on Total Cholesterol

Interaction between SNP rs769450* fat Interaction between SNP rs769450* protein energy \% intake energy \% intake

$-0.01(0.01)$

$0.05(0.02)$

0.10

0.04

Interaction between rs439401 at APOE *dietary factors on Total Cholesterol

Interaction between SNP rs439401* fat energy \% intake

Interaction between SNP rs439401* protein energy \% intake

$-0.003(0.01)$

0.77

$-0.01(0.03)$

0.68

Interaction between rs445925 at APOE *dietary factors on Total Cholesterol

Interaction between SNP rs445925* fat Interaction between SNP rs445925* protein energy \% intake

energy \% intake

$-0.0003(0.01)$

0.97

$-0.02(0.03)$

0.55

Interaction between rs405697 at APOE *dietary factors on Total Cholesterol

Interaction between SNP rs405697* fat Interaction between SNP rs405697* protein energy \% intake energy \% intake

$0.01(0.01)$

$-0.03(0.03)$

0.51

0.24

Interaction between rs1160985 at APOE *dietary factors on Total Cholesterol

Interaction between SNP rs1160985* fat energy \% intake

Interaction between SNP rs1160985* protein energy \% intake

$-0.01(0.01)$

0.13

$-0.004(0.03)$

0.19

Interaction between rs1064725 at APOE * dietary factors on Total Cholesterol

Interaction between SNP rs 1064725* fat Interaction between SNP rs1064725* protein energy \% intake energy \% intake

$-0.01(0.03)$

$0.05(0.11)$

0.62

0.66

Interaction between $A P O E(E 2, E 3 \text {, and } \mathrm{E} 4)^{*}$ dietary factors on Total Cholesterol

Interaction between SNP APOE (E2, E3, and E4)* fat energy \% intake

$-0.02(0.02)$

0.038
Interaction between SNP APOE (E2, E3, and E4)* protein energy \% intake

$0.02(0.04)$

0.83
Interaction between SNP rs405509* carbohydrate energy \% intake

$-0.02(0.01)$

0.31

Interaction between SNP rs $769450^{*}$ carbohydrate energy \% intake

$0.01(0.01)$

0.42

Interaction between SNP rs439401* carbohydrate energy \% intake

$0.004(0.01)$

0.65

Interaction between SNP rs445925* carbohydrate energy \% intake

$0.002(0.01)$

0.87

Interaction between SNP rs405697* carbohydrate energy \% intake

$-0.002(0.01)$

0.84

Interaction between SNP rs1 160985* carbohydrate energy \% intake

$0.01(0.01)$

0.43

Interaction between SNP rs $1064725^{*}$ carbohydrate energy \% intake

$0.01(0.03)$

0.74

Interaction between SNP APOE (E2, E3, and E4)* carbohydrate energy \% intake

$0.01(0.01)$

0.08

Values represented $\beta$ regression coefficients $( \pm S . E)$, and $P_{\text {interaction }}$

$P$ values were obtained by using a general linear model adjusted for age, sex, body mass index, country and total energy intake, wherever appropriate

Bonferroni corrected $P$ value $<0.001$ was considered statistically significant 
acids and total cholesterol [66]. Given that the previous studies have given inconsistent results and have used various types of fatty acids, replication of our gene-diet interaction finding in a large well-designed randomized controlled trial is highly warranted.

Previous studies have shown that the minor allele of LPL SNP rs328 enhance lipolytic activity [12]. Increased activity of LPL results in enhance clearance of TAG from the circulation, and associated with higher HDL-C concentrations [67]. The LPL SNP rs320 (HindIII) is in LD with rs328 (S447X) and they have been shown to have similar effects on HDL-C, where minor allele was reported to increase HDL-C $[24,68]$. In our study, in accordance with findings from other studies, there were associations between LPL SNPs, rs320 and rs328, and HDL-C concentrations, where common homozygotes of both SNPs had lower HDL-C [22-24, 26]. However, in our study, these associations were no longer statistically significant after Bonferroni correction. Furthermore, there were no significant $L P L$ SNP-diet interactions with HDL-C or total cholesterol concentrations in either cohort. To date, there has only been one study that has shown an interaction between $L P L$ rs328 and total fat intake on HDL-C in 8764 individuals from the US population, where high fat intake associated with increase HDL-C in CC homozygotes and CG heterozygotes carriers [28]. One of the main reasons we did not identify a significant interaction may be our small sample size; however, we cannot rule out an effect of differences in dietary fat sources between European and the US population.

The present study has some limitations. Importantly, some lipid-related outcomes, such as LDL-C and TAG concentrations, were not measured in the PRECISE study. The PRECISE study was also conducted in two populations, a UK cohort and a Danish cohort, which used different food frequency questionnaires and this might have introduced measurement bias, even though the current results were adjusted for country in the regression analysis to avoid confounding. Another possible limitation is the use of a cross-sectional design (in both studies) to investigate genetic effects at a single point in time, whereas a longitudinal analysis design would have captured the genetic effects on lipid outcomes over a specific time period. The effect-size of the minor allele of some of the studied SNPs was relatively small, and hence a large sample size is required to detect reliably detect any interaction between SNPs and dietary factors. Despite the fact that this study was not adequately powered to detect such an interaction, it was sufficiently powered to detect the main effects (i.e., associations). Significant gene-diet interactions were identified, however these did not reach the Bonferronicorrected $P$ value $(P=0.001)$ and hence need to be confirmed in larger cohorts. This study is strengthened by the fact that it is the first study to investigate the role of tagSNPs at the $A P O E$ gene in relation to dietary factors and lipid outcomes. The fact that genetic associations from the PRECISE study were replicated in another Caucasian cohort (CaPS) confirms the validity of our findings. Additionally, CaPS was based on a cohort with a very high response rate, and is therefore closely representative of the general population.

\section{Conclusion}

Our study, carried out in two Caucasian populations, confirmed that genetic variations at the $A P O E$ gene locus influence plasma lipid concentrations. Thus, our results suggest that $A P O E$ gene variants affect risk of dyslipidemia in individuals who carry the E4 risk allele and GG genotype at SNP rs445925. Future studies with a larger sample size examining tagSNPs at $A P O E$, particularly prospectively genotyped dietary intervention studies are required to confirm the gene-diet interactions identified in our study.

\section{Additional file}

\section{Additional file 1: Table S1. Genotype distribution of SNPS at $L P L$ and} $A P O E$ genes and Hardy Weinberg Equilibrium $P$ values. (DOCX 18 kb)

\section{Abbreviations \\ APOE: Aspolipoprotein E; CaPS: Caerphilly Prospective cohort; \\ CVD: Cardiovascular disease; FFQ: Food frequency questionnaire; HDL-C: High density lipoprotein cholesterol; HWE: Hardy Weinberg Equilibrium; \\ LD: Linkage disequilibrium; LDL-C: Low density lipoprotein cholesterol; \\ LPL: Lipoprotein lipase; PRECISE: Prevention of Cancer by Intervention with Selenium; SNPs: Single nuclide polymorphisms; TAG: Triacylglycerol; VLDL: Very low density lipoprotein}

\section{Funding}

We acknowledge the support from the British Nutrition Foundation. Genotyping of the genetic variants in the PRECISE study samples were funded by the Saudi government. The PRECISE study was supported by the Danish Cancer Society; the Research Foundation of the County of Funen; Cypress Systems Inc.; the Danish Veterinary and Food Administration; the Council of Consultant Physicians, Odense University Hospital; the Clinical Experimental Research Foundation at Department of Oncology, Odense University Hospital; K.A Rohde's Foundation; Dagmar Marshall's Foundation. Pharma Nord ApS, Vejle, Denmark provided the selenium and placebo tablets. The Caerphilly Prospective Study was undertaken by the former MRC Epidemiology Unit (South Wales) and was funded by the Medical Research Council of the United Kingdom. The Caerphilly DNA Bank was established by an MRC Grant (G9824960). University of Bristol act as the data custodians of CaPS. The funders of the study had no influence on the study design, analysis and interpretation of the data, writing, review, approval or submission of the manuscript.

\section{Authors' contributions}

IMS performed the statistical analysis and drafted the manuscript; KSV conceived and designed the nutrigenetics study; KW and MR designed and conducted the PRECISE study; PE designed and led the conduct of the Caerphilly Prospective study and YBS was involved in the design and conduct of phase $V$ as well as obtaining funding for genetic analysis. JAL, BE, $\mathrm{KW}, \mathrm{MR}, \mathrm{YBS}, \mathrm{PE}, \mathrm{IG}$, and KSV critically reviewed the manuscript. All authors contributed to and approved the final version of the manuscript. 


\section{Ethics approval and consent to participate}

Written informed consent was obtained from each study participant, and the study was approved by the regional Danish Data Protection Agency and Scientific Ethical Committees of Vejle and Funen counties approved the Danish study (PRECISE), the appropriate UK Local Research Ethics Committees [South Tees (ref: 99/69), Worcestershire Health Authority (ref: LREC 74/99), Norwich District (ref: LREC 99/ 141), Great Yarmouth and Waveney (under reciprocal arrangements with Norwich District LREC)] (PRECISE), the South Wales Research Ethics Committee D (CaPS).

\section{Consent for publication}

Written informed consent for publication was obtained from all the study participants.

\section{Competing interests}

The authors declare that they have no competing interests.

\section{Publisher's Note}

Springer Nature remains neutral with regard to jurisdictional claims in published maps and institutional affiliations.

\section{Author details}

${ }^{1}$ Hugh Sinclair Unit of Human Nutrition and Institute for Cardiovascular and Metabolic Research (ICMR), Department of Food and Nutritional Sciences, University of Reading, Whiteknights, PO Box 226, Reading RG6 6AP, UK. ${ }^{2}$ Food and Nutrition Department, Faculty of Home Economics, King Abdulaziz University, Jeddah, Saudi Arabia. ${ }^{3}$ Department of Endocrinology and Metabolism Odense, University Hospital Denmark, Aarhus, Denmark. ${ }^{4}$ Faculty of Health and Social Care, University of Chester, Chester CH1 1SL, UK. ${ }^{5}$ Department of Epidemiology, Statistics and Public Health, Cardiff University, University Hospital of Wales, Heath Park, Cardiff CF14 4XW, UK. ${ }^{6}$ Population Health Sciences, University of Bristol, Bristol BS8 2PS, UK. ${ }^{7}$ Institute for Food, Nutrition and Health, University of Reading, Earley Gate, Reading RG6 6AR, UK. ${ }^{8}$ Department of Nutritional Sciences Faculty of Health and Medical Sciences, University of Surrey, Guildford GU2 7XH, UK.

Received: 25 November 2017 Accepted: 13 April 2018 Published online: 30 April 2018

\section{References}

1. Wang J, et al. The metabolic syndrome predicts cardiovascular mortality: a 13-year follow-up study in elderly non-diabetic Finns. Eur Heart J. 2007;28(7): 857-64

2. McNeill AM, et al. Metabolic syndrome and cardiovascular disease in older people: the cardiovascular health study. J Am Geriatr Soc. 2006;54(9):131724.

3. Barter $\mathrm{P}$, et al. HDL cholesterol, very low levels of $\mathrm{LDL}$ cholesterol, and cardiovascular events. N Engl J Med. 2007;357(13):1301-10.

4. Gotto AM Jr. High-density lipoprotein cholesterol and triglycerides as therapeutic targets for preventing and treating coronary artery disease. Am Heart J. 2002;144(6 Suppl):S33-42

5. Forrester JS. Triglycerides: risk factor or fellow traveler? Curr Opin Cardiol. 2001;16(4):261-4.

6. Song Y, Stampfer MJ, Liu S. Meta-analysis: apolipoprotein E genotypes and risk for coronary heart disease. Ann Intern Med. 2004;141(2):137-47.

7. Ahmadzadeh A, Azizi F. Genes associated with low serum high-density lipoprotein cholesterol. Arch Iran Med. 2014;17(6):444-50.

8. Nettleton JA. Associations between HDL-cholesterol and polymorphisms in hepatic lipase and lipoprotein lipase genes are modified by dietary fat intake in African American and white adults. Atherosclerosis. 2007;194:e13140.

9. Carvalho-Wells AL, et al. APOE genotype influences triglyceride and Creactive protein responses to altered dietary fat intake in UK adults. Am J Clin Nutr. 2012;96(6):1447-53.

10. Couture $P$, et al. Influences of apolipoprotein E polymorphism on the response of plasma lipids to the ad libitum consumption of a highcarbohydrate diet compared with a high-monounsaturated fatty acid diet. Metabolism. 2003;52(11):1454-9.

11. Bennet AM, et al. Association of apolipoprotein E genotypes with lipid levels and coronary risk. JAMA. 2007;298(11):1300-11.
12. Radha $V$, et al. Association of lipoprotein lipase hind III and Ser 447 Ter polymorphisms with dyslipidemia in Asian Indians. Am J Cardiol. 2006;97(9): 1337-42.

13. Shatwan IM, et al. Impact of lipoprotein lipase gene polymorphism, S447X on postprandial triacylglycerol and glucose response to sequential meal ingestion. Int J Mol Sci. 2016;17(3):397.

14. Munshi $A$, et al. Association of LPL gene variant and LDL, HDL, VLDL cholesterol and triglyceride levels with ischemic stroke and its subtypes. J Neurol Sci. 2012;318(1-2):51-4

15. Calabuig-Navarro MV, et al. Apolipoprotein E genotype has a modest impact on the postprandial plasma response to meals of varying fat composition in healthy men in a randomized controlled trial. J Nutr. 2014; 144(11):1775-80.

16. Shahid SU, et al. Effect of SORT1, APOB and APOE polymorphisms on LDL-C and coronary heart disease in Pakistani subjects and their comparison with Northwick Park heart study II. Lipids Health Dis. 2016;15:83.

17. Wilson PW, et al. Apolipoprotein E alleles, dyslipidemia, and coronary heart disease The Framingham Offspring Study. JAMA. 1994;272(21):1666-71.

18. Giger JN, et al. Genetic predictors of coronary heart disease risk factors in premenopausal African-American women. Ethn Dis. 2005;15(2):221-32.

19. Wang $\mathrm{H}$, Eckel $\mathrm{RH}$. Lipoprotein lipase: from gene to obesity. Am J Physiol Endocrinol Metab. 2009;297(2):E271-88.

20. Merkel M, Eckel RH, Goldberg IJ. Lipoprotein lipase: genetics, lipid uptake, and regulation. J Lipid Res. 2002;43(12):1997-2006

21. Friday $\mathrm{KE}$, et al. Black-white differences in postprandial triglyceride response and postheparin lipoprotein lipase and hepatic triglyceride lipase among young men. Metabolism. 1999;48(6):749-54.

22. Nierman MC, et al. Enhanced conversion of triglyceride-rich lipoproteins and increased low-density lipoprotein removal in LPLS447X carriers. Arterioscler Thromb Vasc Biol. 2005;25(11):2410-5.

23. Rip J, et al. Lipoprotein lipase S447X: a naturally occurring gain-of-function mutation. Arterioscler Thromb Vasc Biol. 2006;26(6):1236-45.

24. Lopez-Miranda J, et al. The influence of lipoprotein lipase gene variation on postprandial lipoprotein metabolism. J Clin Endocrinol Metab. 2004;89(9): $4721-8$

25. Sagoo GS, et al. Seven lipoprotein lipase gene polymorphisms, lipid fractions, and coronary disease: a HuGE association review and metaanalysis. Am J Epidemiol. 2008;168(11):1233-46.

26. Ukkola O, et al. Genetic variation at the lipoprotein lipase locus and plasma lipoprotein and insulin levels in the Quebec family study. Atherosclerosis. 2001;158(1):199-206

27. Ordovas JM. Genetic influences on blood lipids and cardiovascular disease risk: tools for primary prevention. Am J Clin Nutr. 2009;89(5):1509s-17s.

28. Nettleton JA, et al. Associations between HDL-cholesterol and polymorphisms in hepatic lipase and lipoprotein lipase genes are modified by dietary fat intake in African American and white adults. Atherosclerosis. 2007:194(2):e131-40

29. Wu K, et al. Apolipoprotein E polymorphisms, dietary fat and fibre, and serum lipids: the EPIC Norfolk study. Eur Heart J. 2007;28(23):2930-6.

30. Zhang C, et al. Interactions between the $-514 C->$ T polymorphism of the hepatic lipase gene and lifestyle factors in relation to HDL concentrations among US diabetic men. Am J Clin Nutr. 2005;81(6):1429-35.

31. Mensink RP, Katan MB. Effect of dietary fatty acids on serum lipids and lipoproteins. A meta-analysis of 27 trials. Arterioscler Thromb. 1992;12(8):911-9.

32. Hwang JY, et al. Carbohydrate intake interacts with SNP276G>T polymorphism in the adiponectin gene to affect fasting blood glucose, $\mathrm{HbA} 1 \mathrm{C}$, and $\mathrm{HDL}$ cholesterol in Korean patients with type 2 diabetes. J Am Coll Nutr. 2013;32(3):143-50.

33. Cold F, et al. Randomised controlled trial of the effect of long-term selenium supplementation on plasma cholesterol in an elderly Danish population. Br J Nutr. 2015;114(11):1807-18.

34. Rayman MP, et al. A randomized trial of selenium supplementation and risk of type-2 diabetes, as assessed by plasma adiponectin. PLoS One. 2012;7(9): e45269.

35. McKeown NM, et al. Use of biological markers to validate self-reported dietary intake in a random sample of the European prospective investigation into Cancer United Kingdom Norfolk cohort. Am J Clin Nutr. 2001;74(2):188-96.

36. Mulligan AA, et al. A new tool for converting food frequency questionnaire data into nutrient and food group values: FETA research methods and availability. BMJ Open. 2014;4(3):e004503. 
37. Komurcu-Bayrak E, et al. The APOE $-219 \mathrm{G} / \mathrm{T}$ and $+113 \mathrm{G} / \mathrm{C}$ polymorphisms affect insulin resistance among Turks. Metabolism. 2011;60(5):655-63.

38. Viiri LE, et al. Interactions of functional apolipoprotein $E$ gene promoter polymorphisms with smoking on aortic atherosclerosis. Circ Cardiovasc Genet. 2008;1(2):107-16.

39. Son KY, et al. Genetic association of APOA5 and APOE with metabolic syndrome and their interaction with health-related behavior in Korean men. Lipids Health Dis. 2015;14:105.

40. Kring Sl, et al. Impact of psychological stress on the associations between apolipoprotein E variants and metabolic traits: findings in an American sample of caregivers and controls. Psychosom Med. 2010;72(5):427-33.

41. Trompet $\mathrm{S}$, et al. Replication of LDL GWAs hits in PROSPER/PHASE as validation for future (pharmaco)genetic analyses. BMC Med Genet. 2011;12:131.

42. Zhang Z, et al. Association of genetic loci with blood lipids in the Chinese population. PLoS One. 2011;6(11):e27305.

43. Zhou $L$, et al. A genome wide association study identifies common variants associated with lipid levels in the Chinese population. PLoS One. 2013;8(12): e82420

44. Seripa $D$, et al. TOMM40, APOE, and APOC1 in primary progressive aphasia and frontotemporal dementia. J Alzheimers Dis. 2012;31(4):731-40.

45. The Caerphilly and speedwell collaborative Group. Caerphilly and Speedwell collaborative heart disease studies. J Epidemiol Community Health. 1984; 38(3):259-62.

46. Mertens $\mathrm{E}$, et al. Dietary patterns in relation to cardiovascular disease incidence and risk markers in a middle-aged British male population: data from the Caerphilly prospective study. Nutrients. 2017;9(1):75.

47. Fehily AM, Yarnell JW, Butland BK. Diet and ischaemic heart disease in the Caerphilly study. Hum Nutr Appl Nutr. 1987;41(5):319-26.

48. Yarnell JW, et al. A short dietary questionnaire for use in an epidemiological survey: comparison with weighed dietary records. Hum Nutr Appl Nutr. 1983;37(2):103-12.

49. Yarnell JW, et al. Do total and high density lipoprotein cholesterol and triglycerides act independently in the prediction of ischemic heart disease? Ten-year follow-up of Caerphilly and speedwell cohorts. Arterioscler Thromb Vasc Biol. 2001;21(8):1340-5.

50. Friedewald WT, Levy RI, Fredrickson DS. Estimation of the concentration of low-density lipoprotein cholesterol in plasma, without use of the preparative ultracentrifuge. Clin Chem. 1972;18(6):499-502.

51. Voight BF, et al. The metabochip, a custom genotyping array for genetic studies of metabolic, cardiovascular, and anthropometric traits. PLoS Genet. 2012;8(8):e1002793.

52. Shah $\mathrm{T}$, et al. Population genomics of cardiometabolic traits: design of the University College London-London School of Hygiene and Tropical Medicine-Edinburgh-Bristol (UCLEB) consortium. PLoS One. 2013;8(8):e71345.

53. El-Lebedy D, Raslan HM, Mohammed AM, Apolipoprotein E. Gene polymorphism and risk of type 2 diabetes and cardiovascular disease. Cardiovasc Diabetol. 2016:15:12.

54. Ken-Dror G, et al. APOE/C1/C4/C2 gene cluster genotypes, haplotypes and lipid levels in prospective coronary heart disease risk among UK healthy men. Mol Med. 2010;16(9-10):389-99.

55. Mozas $P$, et al. Apolipoprotein E genotype is not associated with cardiovascular disease in heterozygous subjects with familial hypercholesterolemia. Am Heart J. 2003;145(6):999-1005.

56. Suwalak T, et al. Polymorphisms of the ApoE (apolipoprotein E) gene and their influence on dyslipidemia in HIV-1-infected individuals. Jpn J Infect Dis. 2015;68(1):5-12.

57. Eichner JE, et al. Apolipoprotein E polymorphism and cardiovascular disease: a HuGE review. Am J Epidemiol. 2002;155(6):487-95.

58. Jackson KG, et al. Saturated fat-induced changes in sf 60-400 particle composition reduces uptake of LDL by HepG2 cells. J Lipid Res. 2006;47(2): 393-403.

59. Ehnholm C, et al. Role of apolipoprotein E in the lipolytic conversion of beta-very low density lipoproteins to low density lipoproteins in type III hyperlipoproteinemia. Proc Natl Acad Sci U S A. 1984;81(17):5566-70.

60. Gregg RE, et al. Abnormal in vivo metabolism of apolipoprotein E4 in humans. J Clin Invest. 1986;78(3):815-21.

61. Smith EN, et al. Longitudinal genome-wide association of cardiovascular disease risk factors in the Bogalusa heart study. PLoS Genet. 2010;6(9): e1001094.

62. Hellwege JN, et al. Genome-wide family-based linkage analysis of exome chip variants and cardiometabolic risk. Genet Epidemiol. 2014;38(4):345-52.
63. Deshmukh HA, et al. Genome-wide association study of genetic determinants of LDL-c response to atorvastatin therapy: importance of Lp(a). J Lipid Res. 2012;53(5):1000-11.

64. Sarkkinen E, et al. Effect of apolipoprotein E polymorphism on serum lipid response to the separate modification of dietary fat and dietary cholesterol. Am J Clin Nutr. 1998;68(6):1215-22.

65. Gylling H, Miettinen TA. Cholesterol absorption and synthesis related to low density lipoprotein metabolism during varying cholesterol intake in men with different apoE phenotypes. J Lipid Res. 1992;33(9):1361-71.

66. Petkeviciene J, et al. Associations between apolipoprotein E genotype, diet, body mass index, and serum lipids in Lithuanian adult population. PLoS One. 2012;7(7):e41525.

67. Kaser S, et al. Phospholipid and cholesteryl ester transfer are increased in lipoprotein lipase deficiency. J Intern Med. 2003;253(2):208-16.

68. Humphries SE, et al. Lipoprotein lipase gene variation is associated with a paternal history of premature coronary artery disease and fasting and postprandial plasma triglycerides: the European atherosclerosis research study (EARS). Arterioscler Thromb Vasc Biol. 1998;18(4):526-34.

\section{Ready to submit your research? Choose BMC and benefit from:}

- fast, convenient online submission

- thorough peer review by experienced researchers in your field

- rapid publication on acceptance

- support for research data, including large and complex data types

- gold Open Access which fosters wider collaboration and increased citations

- maximum visibility for your research: over $100 \mathrm{M}$ website views per year

At BMC, research is always in progress.

Learn more biomedcentral.com/submissions 